\title{
Enzymatic Synthesis of Inulin-Containing Hydrogels
}

\author{
Lino Ferreira, ${ }^{*}, \dagger$ Rui Carvalho, ${ }^{\ddagger}$ Maria H. Gil, ${ }^{\dagger}$ and Jonathan S. Dordick§ \\ Departamento de Engenharia Química, Universidade de Coimbra, Pinhal de Marrocos, \\ 3030 Coimbra, Portugal, Departamento de Bioquímica, Universidade de Coimbra, Apartado 3126, \\ 3000 Coimbra, Portugal, and Department of Chemical Engineering, Rensselaer Polytechnic Institute, \\ 102 Ricketts Building, Troy, New York 12180
}

Received October 5, 2001; Revised Manuscript Received December 14, 2001

\begin{abstract}
The Bacillus subtilis protease Proleather FG-F catalyzed the transesterification of inulin with vinyl acrylate (VA) in dimethylformamide (DMF). The reaction conversion for different VA concentrations was greater than $57 \%$ after $96 \mathrm{~h}$ at $50{ }^{\circ} \mathrm{C}$. The degree of substitution (DS, defined as the amount of acrylate groups per 100 inulin fructofuranoside residues) with acrylate moieties can be controlled by varying the molar ratio of VA to inulin. Reasonable yields were obtained (44-51\%, 2 days) using a two-step purification methodology. Inulin derivatized with VA (Inul-VA) was characterized by gel permeation chromatography, and its structure was established by ${ }^{1} \mathrm{H},{ }^{13} \mathrm{C}$, and ${ }^{1} \mathrm{H}-{ }^{1} \mathrm{H}$ correlation spectroscopy and ${ }^{1} \mathrm{H}-{ }^{13} \mathrm{C}$ heteronuclear multiple quantum coherence NMR. The main positional isomer was at the 6 position of the fructofuranoside residue and two other minor isomers were observed at the 3 and 4 positions. Thus, the enzymatic reaction was largely regioselective. Furthermore, the inulin fructose residues were monosubstituted. Gels with swelling ratios at equilibrium of up to ca. 20 were prepared by free radical polymerization of aqueous solutions of Inul-VA with different DS and monomer concentrations. Gel pore sizes were calculated from swelling experiments and range from 19 to $57 \AA$. To our knowledge, this work reports the first successful enzymatic modification of a polysaccharide solubilized in 100\% DMF solution.
\end{abstract}

\section{Introduction}

Enzymes are effective catalysts for a wide range of reactions because of their high reaction specificity under mild conditions. ${ }^{1}$ This is particularly evident in biotransformations catalyzed by hydrolases (e.g., proteases, lipases, etc.) wherein a variety of nucleophiles act as substrates for enzymecatalyzed acyl transfer in nearly anhydrous organic solvents. ${ }^{2-6}$ This reaction breadth has been extended to polymer synthesis. In particular lipases have been shown to catalyze polytransesterification ${ }^{7,8}$ and ring opening polymerization ${ }^{9,10}$ in organic solvents, and proteases have been used for regioselective synthesis of sugar polyesters in the nonaqueous milieu. ${ }^{11,12}$

Although the traditional uses of enzymes for synthetic applications involve small molecules, the benefits of enzyme technology have been extended to the modification of synthetic and natural polymers, particularly those that are soluble in organic solvents. For example, lipase from Candida antarctica was shown to catalyze the selective epoxidation of polybutadiene in organic solvents in the presence of hydrogen peroxide and catalytic quantities of acetic acid. ${ }^{13}$ Unlike synthetic polymers, polyhydroxylated compounds such polysaccharides either are sparingly soluble in only the most polar organic solvents or are incompletely insoluble. Nevertheless, enzymatic derivatization of polysac-

* To whom correspondence should be addressed. E-mail: linofer3@ eq.uc.pt. Telephone: +351-239-798700. Fax: +351-239-798703.

† Departamento de Engenharia Química, Universidade de Coimbra.

$\doteqdot$ Departamento de Bioquímica, Universidade de Coimbra.

$\S$ Rensselaer Polytechnic Institute. charides has been performed in either nonpolar organic solvents using insoluble polysaccharides with soluble ${ }^{14}$ and suspended enzymes ${ }^{15}$ or aqueous solution using insoluble polysaccharide and soluble enzyme. ${ }^{16}$ The results obtained from nonaqueous enzymatic approaches showed that only surface chains could be enzymatically acylated whereas in aqueous enzymatic solutions it was impossible to control and characterize the reaction products. The rationale of the current work is to overcome these limitations.

Herein we report the first successful enzyme-catalyzed modification of an organic solvent-soluble polysaccharide, inulin, using anhydrous dimethylformamide (DMF) as the reaction medium. Inulin is composed by a mixture of oligomers and polymers containing 2-60 (or more) $\beta-2,1$ linked D-fructose molecules having a glucose unit as the initial residue. ${ }^{17,18}$ While inulin is not digested in the upper gastrointestinal tract, it is hydrolyzed in the colon by intestinal flora. Thus, inulin-based materials may have use as drug delivery matrixes for colonic targeting. These sitespecific delivery systems can be used in the treatment of colonic disorders such as Crohn's disease or colon carcinomas, reducing undesirable side effects caused by chemotherapeutic drugs. ${ }^{17,19}$ For that purpose, we modified inulin with vinyl acrylate (Scheme 1) and then used free radical polymerization to yield cross-linked hydrogels. Hydrogels with different swelling and physical properties were obtained.

\section{Experimental Section}

Materials. Proleather FG-F, a crude serine protease from Bacillus subtilis (molecular weight of approximately 33.4 


\section{Scheme 1}

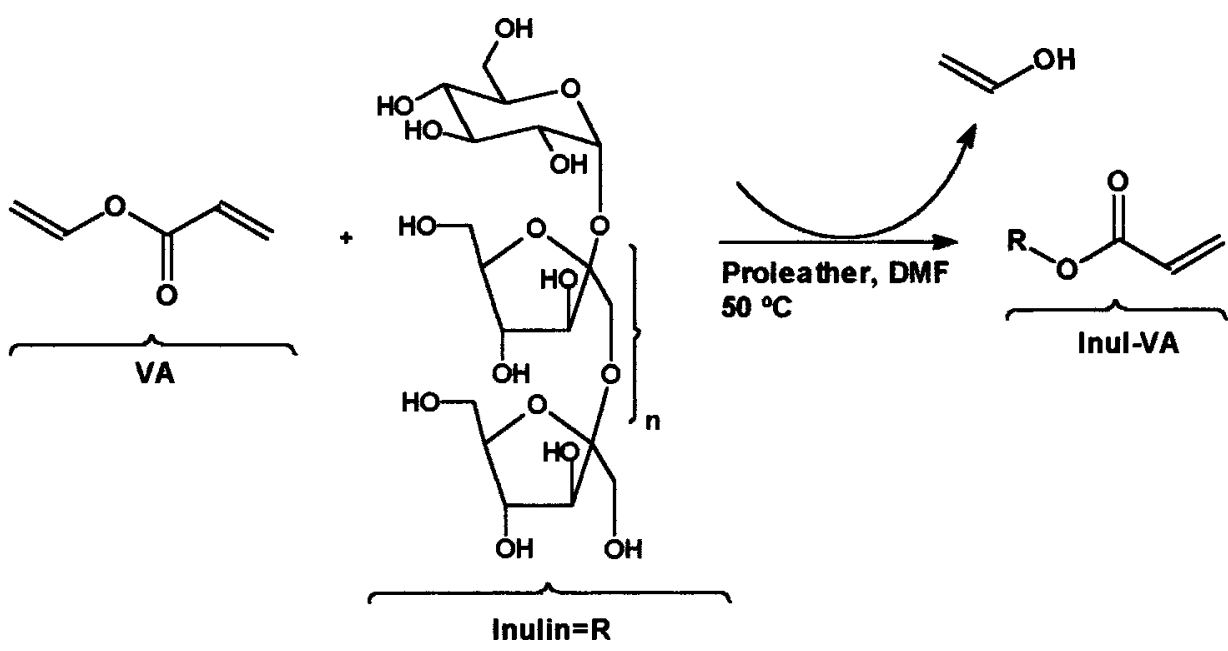

$\mathrm{KDa}$, as determined by electrophoresis assay) was a generous gift from Amano Enzyme Co. (Troy, VA). Chicory inulin $\left(M_{\mathrm{n}}=3620 \mathrm{Da}, M_{\mathrm{w}} / M_{\mathrm{n}}=1.2\right.$, as determined by gel permeation chromatography (GPC) analysis) was purchased from Fluka Chemie AG (Buchs, Switzerland). Vinyl acrylate (VA), $N, N$-dimethylformamide (DMF), $N, N, N^{\prime}, N$ '-tetramethylenethylenediamine (TEMED), and ammonium persulfate (APS) were obtained from Aldrich (Milwauke, WI). DMF was dried with $3 \AA$ molecular sieves at least overnight before use. Regenerated cellulose dialysis tubes with a $1000 \mathrm{MWCO}$ were purchased from Spectrum (CA, USA). All other chemicals and solvents used in this work were of the highest purity commercially available.

Methods. ${ }^{1} \mathrm{H}$ and ${ }^{13} \mathrm{C}$ NMR spectra were recorded on a Varian Unity spectrometer (Palo Alto, CA) at 300 and 75 $\mathrm{MHz}$, respectively. ${ }^{1} \mathrm{H}$ NMR spectra were recorded in $\mathrm{D}_{2} \mathrm{O}$ (60-100 $\mathrm{mg}$ in $0.7 \mathrm{~mL})$ using a pulse angle of $90^{\circ}$ and a relaxation delay of $30 \mathrm{~s}$. The water signal, used as reference line, was set at $\delta 4.75 \mathrm{ppm}$ and was suppressed by irradiation during the relaxation delay. The number of scans in the spectra acquisition was set at $16 .{ }^{13} \mathrm{C} \mathrm{NMR}$ spectra were recorded in $\mathrm{D}_{2} \mathrm{O}$ using a pulse angle of $30^{\circ}$ and relaxation delay of $1 \mathrm{~s}$. tert-Butyl alcohol (tb) was used as reference, which was set at $\delta 31.2 \mathrm{ppm}$ versus tetramethylsilane. Generally, the number of scans was set at 16000 . Bidimensional spectra were recorded on a Varian Unity $500 \mathrm{MHz}$ spectrometer (Palo Alto, CA). ${ }^{1} \mathrm{H}-{ }^{1} \mathrm{H}$ correlation spectroscopy (COSY) spectra were collected as a $1024 \times 416$ matrix covering a $2500 \mathrm{~Hz}$ sweep width using 32 scans/increment. Before Fourier transformation, the matrix was zero filled to $2048 \times 2048$ and standard sine-bell weighting functions were applied in both dimensions. ${ }^{1} \mathrm{H}-{ }^{13} \mathrm{C}$ heteronuclear multiple quantum coherence (HMQC) spectra were collected as a $1024 \times 256$ matrix covering sweep widths of 2500 and $11500 \mathrm{~Hz}$ in the first and second dimensions, respectively. Before Fourier transformation, the matrix was zero-filled to $1024 \times 1024$ and standard Gaussian weighting functions were applied in both dimensions.

The CP/MAS ${ }^{13} \mathrm{C}$ NMR spectra were recorded on a 360 $\mathrm{MHz}$ Chemagnetics spectrometer $(90.5 \mathrm{MHz})$ equipped with CP-MAS (cross-polarization magic-angle-spinning) accessories at $25^{\circ} \mathrm{C}$. The sample (ca. 200-300 mg) was placed in a $7.5 \mathrm{~mm}$ Zirconia rotor (Chemagnetics PENCIL, Fort Collins, CO) and spun at $3 \mathrm{kHz}$. The contact time was $3 \mathrm{~ms}$ and a recycle time of $5 \mathrm{~s}$ was applied. The number of scans was set at 4000 . The ${ }^{13} \mathrm{C}$ shifts were calibrated by substitution using external hexamethylbenzene.

Gel permeation chromatography (GPC) was performed with a Shimadzu LC-10AT (Columbia, MD) equipped with a Waters 410 refractive index detector (Milford, MA). The eluent was DMF at a flow rate of $0.5 \mathrm{~mL} / \mathrm{min}$. Waters 500 and $100 \AA$ Ultrastyragel $(7.5 \times 300 \mathrm{~mm})$, and Styragel HR $5 \mathrm{E}(4.6 \times 300 \mathrm{~mm})$ were installed in series to achieve effective separation of polymers. Calibration was made with polystyrene standards of narrow polydispersity in the molecular weight range from 762 to $44000 \mathrm{Da}$. The GPC chromatograms were obtained from samples dissolved in DMF over a concentration range of $2.1-2.4 \%(\mathrm{w} / \mathrm{v})$.

In some cases (as stated in the text), the determination of degree of substitution (DS) was performed by titration based on a method described by Vervoort et al. ${ }^{20}$ Inulin derivatives (50 mg) were dissolved in $0.1 \mathrm{~N} \mathrm{NaOH}(4 \mathrm{~mL})$ and stirred for $72 \mathrm{~h}$ at $20{ }^{\circ} \mathrm{C}$ to hydrolyze the ester. The molar consumption of $\mathrm{NaOH}$ was determined by back-titration with $0.1 \mathrm{~N} \mathrm{HCl}$ after adding 2 drops of phenolphthalein solution as indicator. Underivatized inulin was used as blank.

Pretreatment of Proleather FG-F and Inulin. Proleather FG-F was "pH-adjusted" in the presence of $20 \mathrm{mM}$ phosphate buffer at $\mathrm{pH}$ 8.0. After flash-freezing in liquid nitrogen, the sample was lyophilized on a Labconco freeze-drier (Labconco Corp., Kansas City, MO) for 48 h. Active site titration was performed before and after lyophilization according to the method of Schonbaum ${ }^{21}$ using $N$-transcinnamoylimidazole as the titrant. The percentage of active enzyme in the commercial powder before and after lyophilization was $4.11 \pm 0.09 \%$ and $2.89 \pm 0.56 \%$ (average \pm standard deviation, $n=3$ ), respectively.

Thermally deactivated Proleather FG-F was prepared by suspending the enzyme in $250 \mathrm{~mL}$ of $20 \mathrm{mM}$ phosphate buffer, $\mathrm{pH} 8.0$, in a $500 \mathrm{~mL}$ round-bottomed flask fitted with a water-cooled condenser. The enzyme solution was refluxed for $5 \mathrm{~h}$ and then was allowed to cool to room temperature and lyophilized. The proteolytic activity of Proleather FG-F and its thermally deactivated preparation were determined 
with casein as the substrate. The enzyme solution $(0.1 \mathrm{~mL}$, $80 \mathrm{mg} / \mathrm{mL}$ ) was added to the reaction media formed by a mixture of $1 \mathrm{~mL}$ of $0.1 \mathrm{M}$ phosphate buffer $\mathrm{pH} 8.0$ with 5 $\mathrm{mL}$ of $1.0 \%(\mathrm{w} / \mathrm{v})$ casein solution. The mixture was incubated for $3 \mathrm{~min}$ at $37^{\circ} \mathrm{C}$, with magnetic stirring (200 $\mathrm{rpm}$ ), and a $0.5 \mathrm{~mL}$ aliquot was taken and added to an equal volume of $0.4 \mathrm{M}$ trichloroacetic acid. The resulting precipitate was removed by centrifugation ( $5000 \mathrm{rpm}, 2 \mathrm{~min}$ ) after standing for $25 \mathrm{~min}$ at $25^{\circ} \mathrm{C}$. The supernatant $(0.5 \mathrm{~mL})$ was placed in a test tube containing $5 \mathrm{~mL}$ of $0.4 \mathrm{M}$ sodium carbonate and $0.5 \mathrm{~mL}$ of 5-fold diluted Folin's reagent. After thorough mixing, the solution was allowed to stand for 20 min at $37{ }^{\circ} \mathrm{C}$, and the absorbance measured spectrophotometrically at $660 \mathrm{~nm}$. The absorbance values were then converted to equivalent tyrosine concentration using a tyrosine calibration curve. One unit of protease activity (U) is defined as quantity of enzyme needed to produce the amino acid equivalent of $1 \mu \mathrm{g}$ of tyrosine/min.

In some cases, as stated on the text, inulin was treated before reaction. Inulin $(6.7 \%, \mathrm{w} / \mathrm{v})$ was dissolved in $300 \mathrm{~mL}$ of DMF and further centrifuged at $4000 \mathrm{rpm}$ for $5 \mathrm{~min}$. The supernatant was precipitated in $500 \mathrm{~mL}$ of acetone, and the precipitate was dissolved in water and lyophilized for $48 \mathrm{~h}$.

Enzymatic Synthesis of Inulin Ester Monomers. Preparative-scale reactions were performed in $60 \mathrm{~mL}$ of anhydrous DMF containing $0.017 \mathrm{M}(6.7 \%$, w/v) inulin and variable concentrations of VA. The reaction mixtures were shaken $(250 \mathrm{rpm})$ at $50^{\circ} \mathrm{C}$ in a temperature-controlled New Brunswick Scientific C24 orbital shaker (Edison, NJ) for 96 $\mathrm{h}$. The reactions were terminated by removal of the enzyme (which is insoluble in DMF) by centrifugation at $4000 \mathrm{rpm}$ for $10 \mathrm{~min}$. The supernatants were precipitated in a 4-fold excess of acetone and further washed with the same solvent. The precipitate was subsequently dissolved in Milli-Q water and dialyzed using a regenerated cellulose dialysis tube with a $1000 \mathrm{MWCO}$ for 2 days, at $4{ }^{\circ} \mathrm{C}$, against water. Afterward, the aqueous solutions of Inul-VA were lyophilized for $48 \mathrm{~h}$.

Time course reactions of inulin ester synthesis by Proleather FG-F $(10,20$, and $30 \mathrm{mg} / \mathrm{mL})$ were performed independently in $15 \mathrm{~mL}$ of anhydrous DMF containing 0.017 M (6.7\%, w/v) inulin and 0.204 M VA (molar ratio of vinyl monomer to inulin fructofuranoside residues of $50 \%$ ) at 250 $\mathrm{rpm}$ and $50{ }^{\circ} \mathrm{C}$. The purification of the products was performed as before.

Preparation of Inul-VA Gels. Inul-VA gels were obtained by free radical polymerization of aqueous solutions of InulVA as a function of DS and monomer concentration. InulVA $(100,200$, or $400 \mathrm{mg})$ was dissolved in $0.9 \mathrm{~mL}$ of 0.2 $\mathrm{M}$ phosphate buffer $\mathrm{pH} 8.0$, and the polymerization reaction performed in $2 \mathrm{~mL}$ plastic Eppendorf tubes $(\cong 0.5 \mathrm{~cm}$ radius) was initiated by adding $50 \mu \mathrm{L}$ of APS $(80 \mathrm{mg} / \mathrm{mL}$ in $0.2 \mathrm{M}$ phosphate buffer $\mathrm{pH}$ 8.0) and $50 \mu \mathrm{L}$ of TEMED solution $(13.6 \%(\mathrm{v} / \mathrm{v})$ in water; adjusted to $\mathrm{pH} 8.0$ with $12 \mathrm{~N} \mathrm{HCl})$ for $24 \mathrm{~h}$ at $25^{\circ} \mathrm{C}$. The gels were subsequently removed from the Eppendorf tubes and immersed in $100 \mathrm{~mL}$ of $0.010 \mathrm{M}$ citrate-phosphate buffer $\mathrm{pH} 7.0$, for 5 days at $25{ }^{\circ} \mathrm{C}$, changing the buffer daily. At regular intervals, the swollen gels were removed, blotted with filter paper to remove surface water, weighed, and returned to the same container until weight stabilization was observed (5 days). The gels were then dried at room temperature, under vacuum, in the presence of phosphorus pentoxide, and weighed to determine the dried weight, $W_{\mathrm{d}}$. The swelling ratio at equilibrium (SRE) was calculated according to eq 1 .

$$
\mathrm{SRE}=\frac{W_{\mathrm{s}}-W_{\mathrm{d}}}{W_{\mathrm{d}}}
$$

The molecular weight between cross-links $\left(\bar{M}_{\mathrm{c}}\right)$ was calculated with the model of Flory and Rehner, ${ }^{22}$ modified by Peppas et al., ${ }^{23}$ according to the implicit eq 2

$$
\begin{aligned}
& \frac{1}{\bar{M}_{\mathrm{c}}}=\frac{2}{\bar{M}_{\mathrm{n}}}- \\
& \frac{\left(\frac{\bar{v}}{V_{1}}\right)\left[\ln \left(1-v_{2, \mathrm{~s}}\right)+v_{2, \mathrm{~s}}+\chi_{1}\left(v_{2, \mathrm{~s}}\right)^{2}\right]\left[1-\frac{1}{\chi_{\mathrm{c}}}\left(\frac{v_{2, \mathrm{~s}}}{v_{2, \mathrm{r}}}\right)^{2 / 3}\right]^{3}}{v_{2, \mathrm{r}}\left[\left(\frac{v_{2, \mathrm{~s}}}{v_{2, \mathrm{r}}}\right)^{1 / 3}-0.5\left(\frac{v_{2, \mathrm{~s}}}{v_{2, \mathrm{r}}}\right)\right]\left[1+\frac{1}{\chi_{\mathrm{c}}}\left(\frac{v_{2, \mathrm{~s}}}{v_{2, \mathrm{r}}}\right)^{1 / 3}\right]^{2}}
\end{aligned}
$$

where $\bar{M}_{\mathrm{n}}$ is number average molecular weight of the inulin used $(3620 \mathrm{Da}), v$ is the partial specific volume of inulin $\left(0.601 \mathrm{~cm}^{3} / \mathrm{g}\right),{ }^{24} V_{1}$ is the molar volume of water $\left(18 \mathrm{~cm}^{3} /\right.$ g), $\chi_{1}$ is the Flory polymer-solvent interaction parameter $\left(0.473\right.$ taken from dextran/water system $\left.{ }^{25}\right), \chi_{\mathrm{c}}$ is the number of links of the chain $\left(\chi_{\mathrm{c}}=2 \bar{M}_{\mathrm{c}} / M_{\mathrm{r}}\right.$, where $M_{\mathrm{r}}$ is the molecular weight of the inulin repeating unit, 162.14), $v_{2, \mathrm{r}}$ is the polymer fraction of the gel after gel formation and $v_{2, \mathrm{~s}}$ is the polymer fraction at equilibrium swelling. $v_{2, \mathrm{r}}$ and $v_{2, \mathrm{~s}}$ were calculated from the weight of the gels before exposure to the buffer solution and after equilibrium swelling, respectively, assuming volume additivity of water and inulin. The average mesh size, $\xi$, was calculated through the use of eqs 3 and $4^{23}$

$$
\begin{gathered}
\bar{r}_{\mathrm{o}}^{2}=C_{\mathrm{n}} \chi_{\mathrm{c}} b^{2} \\
\xi=v_{2, \mathrm{~s}}{ }^{-1 / 3}\left(\bar{r}_{\mathrm{o}}^{2}\right)^{1 / 2}
\end{gathered}
$$

where $\bar{r}_{\mathrm{o}}^{2}$ represents the average end-to-end subchain length (in $\AA$ ) when the gel is unswollen, $C_{\mathrm{n}}$ is the polymer rigidity factor, assumed to be 8.9 by analogy to polar poly(vinyl alcohol), ${ }^{26}$ and $b$ is the characteristic bond length of the polymer backbone ( $=1.54 \AA$, corresponding to the $\mathrm{C}-\mathrm{C}$ bond length).

\section{Results and Discussion}

Synthesis of VA Derivatized Inulin. Recently we found that Proleather FG-F enzyme was able to acylate inulin with divinyl adipate in DMF (unpublished results), ${ }^{27}$ from a group of 11 commercially available proteases and lipases, and therefore was chosen in this present work. VA was selected as an activated acrylate acyl donor that is known for its high reactivity in enzyme-catalyzed transesterification reactions. ${ }^{28}$ The time-course reaction of inulin with VA, at $50{ }^{\circ} \mathrm{C}$, at increasing concentrations of enzyme is shown in Figure 1. As expected, the initial reaction rate increases as a function of the enzyme concentration. Quantitative measurement of 


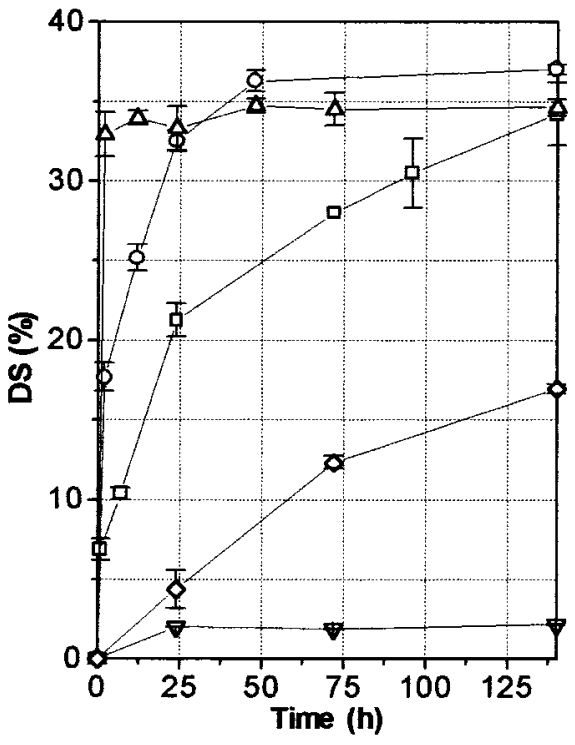

Figure 1. DS obtained as a function of time for the reaction of VA with inulin (molar ratio of VA to inulin fructofuranoside residues was $50 \%)$ in a concentration of $6.7 \%(\mathrm{w} / \mathrm{v})$ in either the absence $(\nabla)$ or presence of $10 \mathrm{mg} / \mathrm{mL}(\square), 20 \mathrm{mg} / \mathrm{mL}(\bigcirc)$, and $30 \mathrm{mg} / \mathrm{mL}(\triangle)$ of Proleather as catalyst, or $20 \mathrm{mg} / \mathrm{mL}$ of thermally deactivated Proleather $(\diamond)$, at $50^{\circ} \mathrm{C}$. Values were determined by titration (average \pm standard deviation, $n=3$ ).

acrylate incorporation onto the inulin backbone was possible in $2 \mathrm{~h}$, when $30 \mathrm{mg} / \mathrm{mL}$ of Proleather was used. Further analysis of Figure 1 reveals that DS (corresponding to a conversion ${ }^{29}$ of ca. $70 \%$ ) of Inul-VA is practically unchanged after $50 \mathrm{~h}$, for Proleather FG-F concentrations of 20 and 30 $\mathrm{mg} / \mathrm{mL}$, indicating that all the reactive sites on inulin have acrylate functionalities attached.

In parallel to these time-course reactions with Proleather, control reactions in the absence or with thermally deactivated enzyme were also carried out (Figure 1). In the absence of added active enzyme no significant (DS ca. 2\%) inulin derivatization occurred in $140 \mathrm{~h}$ of reaction. However, unexpectedly, the addition of Proleather thermally deactivated for $5 \mathrm{~h}$ at $100^{\circ} \mathrm{C}$ did catalyze a noticeable transesterification of inulin with VA to give a DS of ca. $17 \%$ after $140 \mathrm{~h}$. To assess whether this conversion could be a result of nonspecific reactions due to nucleophilic functionalities in the protein preparation, or due to a true intrinsic catalytic residual enzymatic activity, the proteolytic activity of the heat-treated enzyme preparation was measured using casein as substrate. It was found that active Proleather FG-F and its deactivated preparation had activity values of $104.9 \pm 7.9$ and $10.3 \pm$ $0.3 \mathrm{U} / \mathrm{mL}$ of enzyme solution, respectively, and this corresponded to a similar ratio of reactivities using $20 \mathrm{mg} / \mathrm{mL}$ Proleather on inulin. Thus, it may be concluded that the residual inulin activity present in the heat-treated Proleather was due to intrinsic activity, and this further suggests that the enzyme is highly thermostable. Furthermore, we found that some enzymes did not present any activity on the polytransesterification reaction of inulin with divinyl adipate, ${ }^{27}$ further corroborating the absence of nonspecific reactions due to their external amino acids (not involving the catalytic site). On the basis of these results, we performed preparative-scale synthesis of inulin esters for $96 \mathrm{~h}$ in the presence of $20 \mathrm{mg} / \mathrm{mL}$ Proleather at $50{ }^{\circ} \mathrm{C}$.

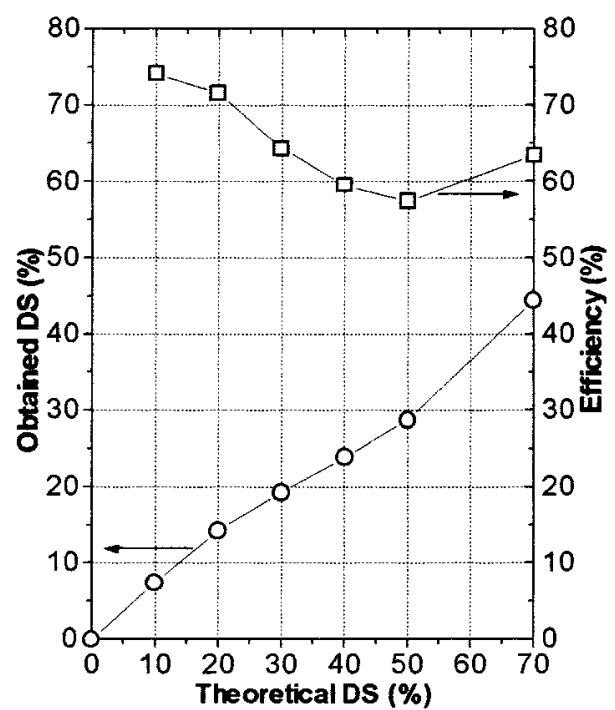

Figure 2. Relationship between the theoretical and the obtained DS for Inul-VA as determined by ${ }^{1} \mathrm{H}$ NMR. The efficiency was calculated as the ratio of the obtained DS to the theoretical DS.

Figure 2 shows the relationship between the molar ratio of VA to inulin fructose units in the reaction mixture (theoretical DS) and the degree of substitution of the products, as determined by ${ }^{1} \mathrm{H}$ NMR (obtained DS). From these results, Inul-VA can be obtained with different DS, ranging the concentration of the acyl donors. The efficiency of the coupling reaction (calculated as the ratio of the obtained DS to the theoretical DS) was above $57.4 \%$.

The two-step purification procedure adopted in this work, based on a precipitation with acetone followed by dialysis against water, was revealed to be an efficient way to obtain ester products (isolated yield of $44-51 \%$, except for InulVA DS $44.4 \%$, which had an isolated yield of $27.7 \%$ ) with no impurities as detected by ${ }^{1} \mathrm{H}$ NMR spectroscopy and further confirmed by elemental analysis (nitrogen content was below $0.5 \%$ ). Yet due to the easy removal of Proleather enzyme from the reaction mixture (insoluble in DMF), the purification protocol is faster than the one presented by Vervoort et al. ${ }^{20}$ which employed an extensive dialysis process for 10 days to remove the catalyst 4-(dimethylamino)pyridine in the methacrylation of inulin.

GPC Analysis. GPC analysis of Inulin and Inul-VA derivatives showed different elution profiles. Representative chromatograms of these polymers are presented in Figure 3. The inulin GPC chromatogram shows a single peak corresponding a $M_{\mathrm{n}}$ of $3620 \mathrm{Da}\left(M_{\mathrm{w}} / M_{\mathrm{n}}=1.2\right)$ and an average degree of polymerization of 25 . The same profile was not observed for Inul-VA samples with different DS values. Chromatograms $\mathrm{B}$ and $\mathrm{C}$ present a major peak (B1 or $\mathrm{C} 1$ ) and two other minor peaks (B2 and B3, $M_{\mathrm{n}}$ of 13450 and $35160 \mathrm{Da}$, respectively; C2 and C3, $M_{\mathrm{n}}$ of 12180 and 31640 $\mathrm{Da}$, respectively). The major inulin peak in those samples is shifted to higher molecular weight from $M_{\mathrm{n}} 4100 \mathrm{Da}$ to $M_{\mathrm{n}}$ $4440 \mathrm{Da}$ when DS values increase. This is likely due to introduction of acrylate groups in the inulin backbone. The minor peaks in chromatogram B and C (representing 12.4\% and $19.7 \%$ of the sample, respectively) may be from high molecular weight polymers in the inulin which were not originally soluble in DMF but soluble after derivatization 


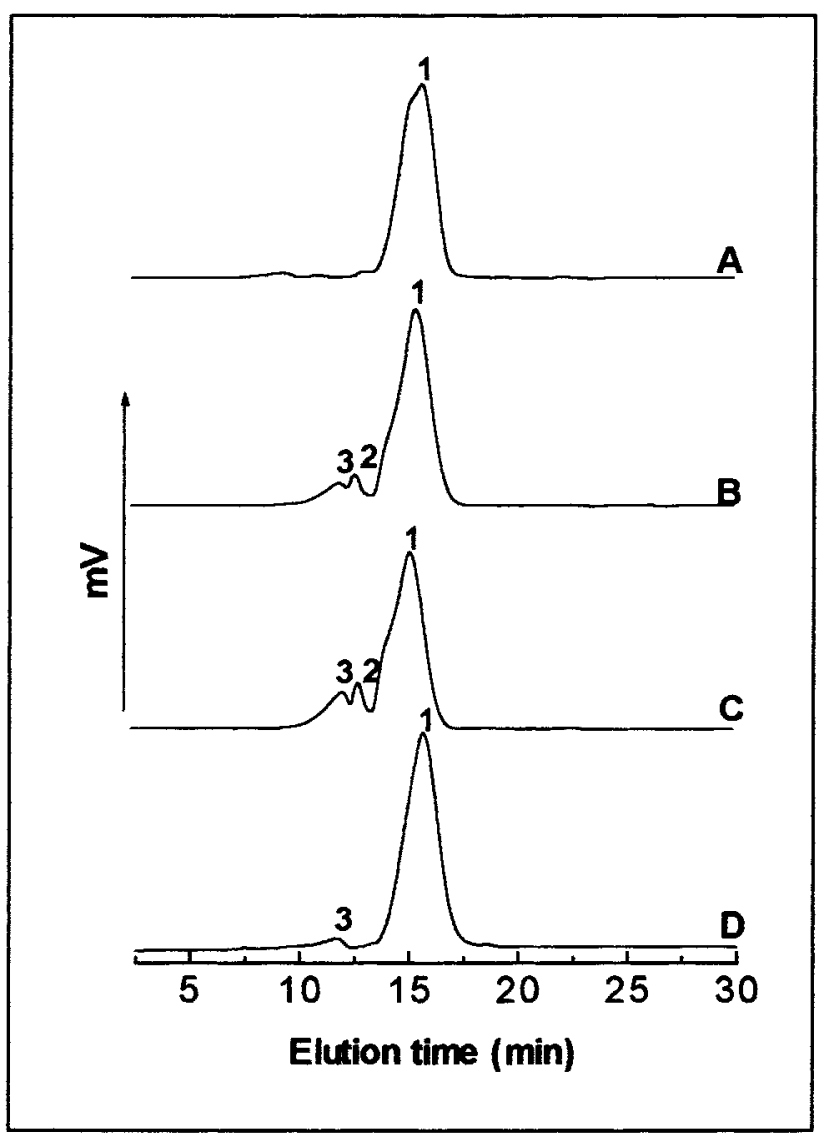

Figure 3. GPC chromatograms of inulin (A) and Inul-VA (B, C, D). Inul-VA samples were obtained from either original inulin $(B, C)$ or acetone-precipitated inulin (D) as starting polymers for the transesterification reaction. The DS for Inul-VA samples was $21.2 \%(B)$, $34.2 \%(C)$, and $17.7 \%(D)$.

with VA. It is noteworthy to mention that traces of original inulin were not completely soluble in DMF, and therefore its GPC analysis (chromatogram A), using DMF as eluent, shows just the soluble moiety. As the transesterification reaction proceeds, high molecular weight polymers may become soluble in DMF due to modification with the relatively hydrophobic VA. This was further verified by removing the DMF-insoluble fraction of inulin by centrifugation and precipitating the supernatant in acetone. The precipitated inulin was reacted with VA in the presence of Proleather and the reaction product characterized by GPC. The GPC chromatogram obtained (D) shows that one of the minor peaks is totally removed (corresponding to B2 and $\mathrm{C} 2$ ) and the other one is partially removed (corresponding to B3 and C3). Even if the removal of minor peaks was not complete the results suggest that those peaks are related to high molecular weight polymers. Similar results showing small amounts of high molecular weight polymers on inulin were described by Verraest et al. ${ }^{30}$ by GPC analysis using $0.1 \mathrm{M} \mathrm{NaNO}_{3}$ as eluent.

Characterization by NMR spectroscopy. The structure of Inul-VA was analyzed by NMR spectroscopy. Figure 4 displays ${ }^{1} \mathrm{H}(\mathrm{A})$ and ${ }^{13} \mathrm{C}$ (B) NMR spectra of Inul-VA. In the ${ }^{1} \mathrm{H}$ NMR spectrum (spectrum A) the intense peaks between $\delta 3.38$ and $4.23 \mathrm{ppm}$ are attributed to protons of unreacted inulin, including the anomeric proton at $\delta 5.42$

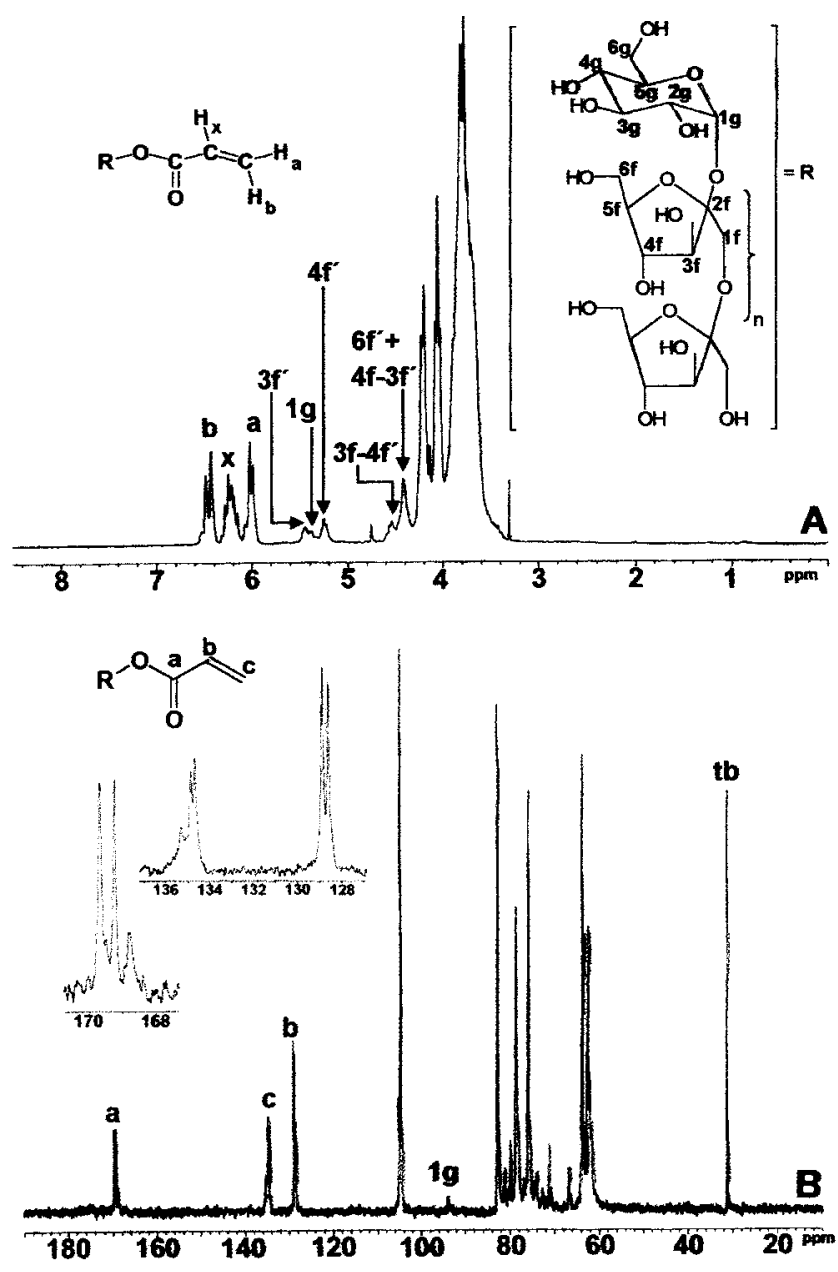

Figure 4. ${ }^{1} \mathrm{H}(\mathrm{A})$ and ${ }^{13} \mathrm{C}(\mathrm{B}) \mathrm{NMR}$ spectra of Inul-VA (DS $=28.7 \%$ ) in $\mathrm{D}_{2} \mathrm{O}$, at $25^{\circ} \mathrm{C}$.

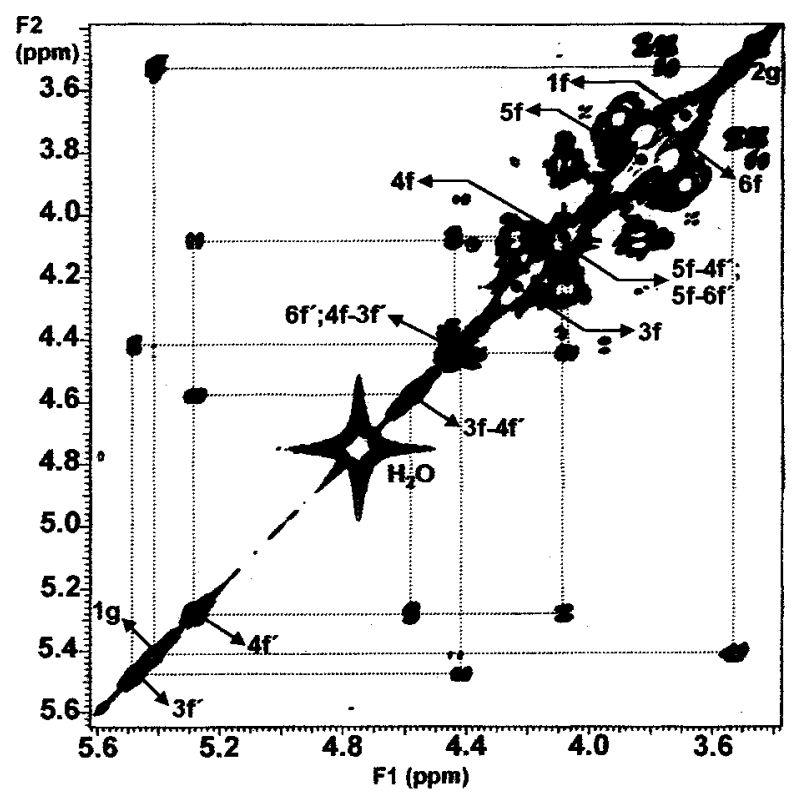

Figure 5. ${ }^{1} \mathrm{H}-{ }^{1} \mathrm{H}$ COSY spectrum of Inul-VA (DS $=19.3 \%$ ) in $\mathrm{D}_{2} \mathrm{O}$ at $25^{\circ} \mathrm{C}$, showing the ${ }^{1} \mathrm{H}-{ }^{1} \mathrm{H}$ correlations important for the assignment (see text for more details).

ppm belonging to the D-glucopyranosyl units. The assignments of each proton signal are clearly shown in the ${ }^{1} \mathrm{H}-{ }^{1} \mathrm{H}$ COSY displayed in Figure 5. Furthermore, from the ${ }^{1} \mathrm{H}$ NMR spectrum of Inul-VA signals from the acrylate groups are observed at $\delta 6.4 \mathrm{ppm}\left(\mathrm{H}_{\mathrm{b}},{ }^{3} J_{\mathrm{bx}}=17.21 \mathrm{~Hz},{ }^{2} J_{\mathrm{ba}}=1.47\right.$ 
Table 1. ${ }^{13} \mathrm{C}$ NMR Assignments of the Fructofuranosyl Ring Carbons $(\delta, \mathrm{ppm})$ on Inul-VA with DS $28.7 \%$

\begin{tabular}{|c|c|c|c|c|c|c|c|}
\hline \multirow[b]{3}{*}{ carbon } & \multirow{3}{*}{$\begin{array}{l}\frac{\text { inulin }}{\text { obsd }} \\
\text { signal }\end{array}$} & \multicolumn{6}{|c|}{ Inul-VA } \\
\hline & & \multicolumn{2}{|c|}{ 6-substituted } & \multicolumn{2}{|c|}{ 4-substituted } & \multicolumn{2}{|c|}{ 3-substituted } \\
\hline & & $\begin{array}{l}\text { obsd } \\
\text { signal }\end{array}$ & $\Delta \delta$ & $\begin{array}{l}\text { obsd } \\
\text { signal }\end{array}$ & $\Delta \delta$ & $\begin{array}{l}\text { obsd } \\
\text { signal }\end{array}$ & $\Delta \delta$ \\
\hline 1 & 62.4 & 62.1 & -0.3 & 61.9 & -0.5 & 61.7 & -0.7 \\
\hline 2 & 104.8 & 104.7 & -0.1 & 105.0 & +0.2 & 105.3 & +0 \\
\hline 3 & 78.6 & 78.4 & -0.2 & 76.9 & -1.7 & 80.6 & +2.0 \\
\hline 4 & 75.8 & 76.1 & +0.3 & 78.2 & +2.4 & 74.6 & -1.2 \\
\hline 5 & 82.6 & 80.0 & -2.6 & 81.2 & -1.4 & 82.4 & -0.2 \\
\hline 6 & 63.7 & 66.8 & +3.1 & 63.5 & -0.2 & 63.9 & +0 \\
\hline
\end{tabular}

$\mathrm{Hz}), \delta 6.2 \mathrm{ppm}\left(\mathrm{H}_{x},{ }^{3} J_{\mathrm{xa}}=10.38 \mathrm{~Hz},{ }^{3} J_{\mathrm{xb}}=17.21 \mathrm{~Hz}\right), \delta$ $6.0 \mathrm{ppm}\left(\mathrm{H}_{\mathrm{a}},{ }^{3} J_{\mathrm{ax}}=10.38 \mathrm{~Hz},{ }^{2} J_{\mathrm{ab}}=1.47 \mathrm{~Hz}\right)$.

The formation of Inul-VA is also confirmed by its ${ }^{13} \mathrm{C}$ NMR spectrum (Figure 4, spectrum B). The fructofuranosyl and acrylate carbons are displayed in the range of 62.0105.2 and 128.6-169.7 ppm, respectively. Except for carbon $\alpha$ (denoted as b in Figure 4) of the double bond (duplicate: 128.9 and $128.6 \mathrm{ppm})$, all other signals are in triplicate $\left(\mathrm{C}_{\mathrm{a}}\right.$ : $169.7,169.2$, and $168.8 \mathrm{ppm} ; \mathrm{C}_{\mathrm{c}}: 135.3,134.9$, and 134.7). This indicates the presence of three different positional isomers in the Inul-VA product.

The ester positions on the fructofuranosyl ring were assigned based on the additional signals presented in ${ }^{13} \mathrm{C}$ NMR spectrum (Figure 4) of Inul-VA ranging from $\delta 105.2$ to $62.0 \mathrm{ppm}$. According to the literature ${ }^{31}$ chemical shifts of acylated carbons suffer a downfield shift and the respective adjacent carbons a concomitant upfield shift. The chemical shifts of the other carbon atoms are hardly affected. As shown in the ${ }^{13} \mathrm{C}$ NMR spectrum there is no upfield shift of $\mathrm{C}-2$ carbons, which appears to indicate no positional isomer at position 3. Therefore, the two acylated isomers in the main inulin backbone are at positions 6 and 4 in the fructofuranosyl ring. The respective ${ }^{13} \mathrm{C}$ NMR assignments are presented in Table 1. An ${ }^{1} \mathrm{H}-{ }^{13} \mathrm{C}$ HMQC NMR experiment was performed to correlate those ${ }^{13} \mathrm{C}$ signals with ${ }^{1} \mathrm{H}$ signals (Figure 6). In this spectrum the ${ }^{13} \mathrm{C}$ peaks at $\delta 66.8 \mathrm{ppm}$ (modification at 6 position) and $\delta 78.2 \mathrm{ppm}$ (modification at 4-position) are correlated with ${ }^{1} \mathrm{H}$ signals at $\delta 4.41 \mathrm{ppm}\left(6 \mathrm{f}^{\prime}\right)$ and $\delta$ $5.24 \mathrm{ppm}\left(4 \mathrm{f}^{\prime}\right)$, respectively. From ${ }^{1} \mathrm{H}-{ }^{1} \mathrm{H}$ COSY (Figure $5)$ the signal at $\delta 5.24 \mathrm{ppm}$ has two cross-peaks at 4.58 and $4.08 \mathrm{ppm}$ corresponding to the vicinal protons at positions 3 (denoted as $\left.3 \mathrm{f}-4 \mathrm{f}^{\prime}\right)$ and $5\left(5 \mathrm{f}-4 \mathrm{f}^{\prime}\right)$, while the signal at $\delta$ $4.41 \mathrm{ppm}$ has a single correlation with a peak at $4.09 \mathrm{ppm}$ corresponding to a vicinal proton at position $5\left(5 \mathrm{f}-6 \mathrm{f}^{\prime}\right)$.

However, still remaining is the assignment of the third isomer. In the ${ }^{1} \mathrm{H}$ NMR spectrum of Inul-VA there is a small signal at $\delta 5.45 \mathrm{ppm}$ that overlaps with the D-glucopyranosyl anomeric proton at $5.42 \mathrm{ppm}$, the latter correlating in the ${ }^{1} \mathrm{H}-{ }^{13} \mathrm{C}$ HMQC spectrum with a ${ }^{13} \mathrm{C}$ signal at $\delta 80.6 \mathrm{ppm}$. This signal corresponds to an acylated carbon at position 3 (Table 1). This is further confirmed by the ${ }^{1} \mathrm{H}-{ }^{1} \mathrm{H}$ COSY spectrum, which shows a single cross-peak for this signal at $4.42 \mathrm{ppm}$ corresponding to a vicinal proton at position 4 (4f$\left.3 \mathrm{f}^{\prime}\right)$. Interestingly, as previously mentioned, there is no upfield shift in the ${ }^{13} \mathrm{C}$ NMR spectrum corresponding to the $\mathrm{C}-2$ position, as would be expected according to the

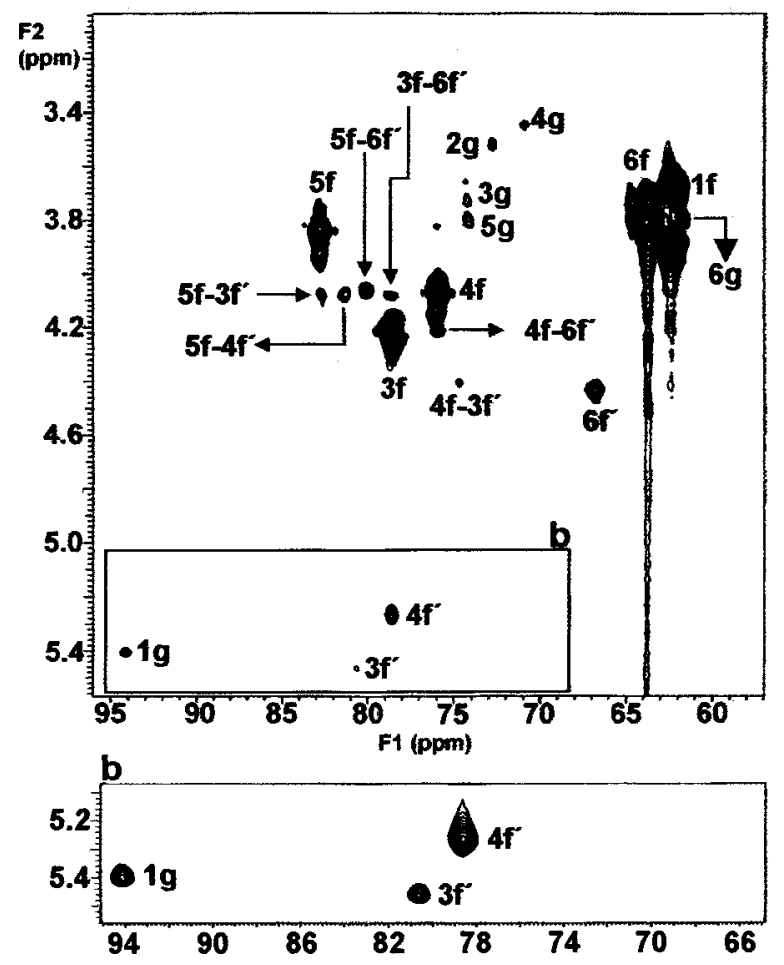

Figure 6. ${ }^{1} \mathrm{H}-{ }^{13} \mathrm{C} \mathrm{HMQC}$ spectrum of Inul-VA (DS $=19.3 \%$ ) in $\mathrm{D}_{2} \mathrm{O}$ at $25^{\circ} \mathrm{C}$, showing the ${ }^{1} \mathrm{H}-{ }^{13} \mathrm{C}$ correlations (see text for more details).

literature. ${ }^{31}$ This might be due to the absence of protons attached to that carbon, thereby mitigating the observed upfield shift.

On the basis of the ${ }^{1} \mathrm{H}$ NMR assignments, the DS was determined using eq 5

$$
\mathrm{DS}=(7 x / y) * 100
$$

where $x$ is the average integral of the protons from vinyl group $(\delta 6.0-6.4 \mathrm{ppm})$ and $y$ is the integral of all inulin protons.

Distribution of the Acrylate Substituents. On the basis of the ${ }^{1} \mathrm{H}$ NMR assignments (Figure 4, spectrum A) the relative $\mathrm{DS}\left(\mathrm{DS}_{i}\right)$ of modified individual hydroxyl groups attached to the C-3, C- 4 , and C- 6 carbons have been estimated from the following equations

$$
\begin{gathered}
\mathrm{DS}_{3}=[x(\mathrm{DS})] / y \\
\mathrm{DS}_{4}=[z(\mathrm{DS})] / y \\
\mathrm{DS}_{6}=[(x+z)-\mathrm{DS}] / y
\end{gathered}
$$

where $x$ and $z$ are the integral of the proton signals at $\delta 5.45$ and $\delta 5.24 \mathrm{ppm}$, respectively; $y$ is the average integral of the protons from vinyl group $(\delta 6.0-6.4 \mathrm{ppm})$; and DS is the total degree of substitution calculated from eq 5. By use of these equations the distribution of substituents in InulVA samples with different DS was calculated and presented in Figure 7. The results obtained indicate that the reactivity of hydroxyl groups toward acylation reaction decreases in the order $\mathrm{C} 6 f>\mathrm{C} 4 f>\mathrm{C} 3 f$, where $f$ indicates the fructosyl moiety. Since ${ }^{1} \mathrm{H}-{ }^{1} \mathrm{H}$ COSY clearly indicates that all fructose units substituted are monosubstituted (no cross-peaks are shared by the three positional isomers), the relative reac- 


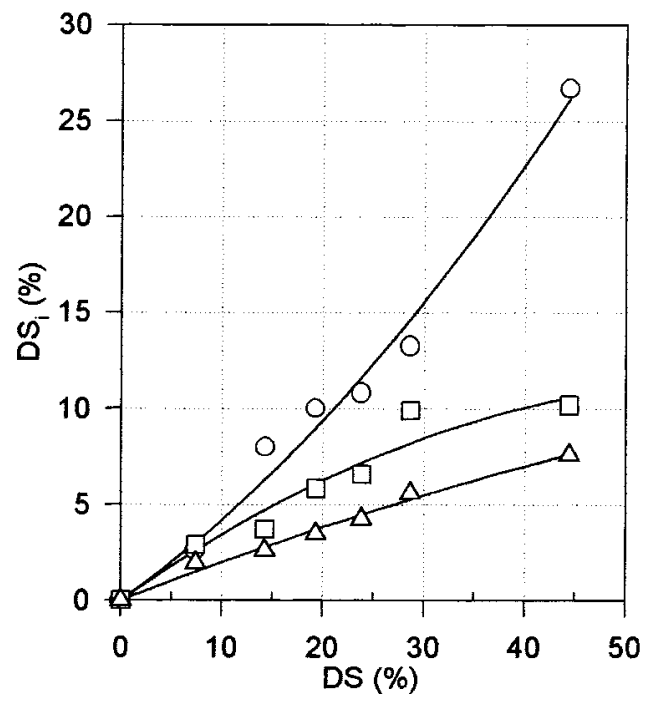

Figure 7. Variation of DS at hydroxyl groups $\left(D S_{i}\right)$ in positions 6 $(O), 4(\square)$, and $3(\triangle)$ with the total degree of substitution in Inul-VA (DS).

tivities of the hydroxyl groups are not influenced by substitution of other positions in the unit. Furthermore, as shown in Figure 7, the relative reactivities of the hydroxyl groups are independent of the DS, which demonstrates that the acylation of a particular hydroxyl group follows an independent trend.

The substitution pattern achieved in the Inul-VA samples with different DS shows the expected enzyme's preference for primary hydroxyl groups and agreement with results described in the literature showing that enzymatic acylation of small nucleophiles, including sugars, occurs preferentially at the primary hydroxyl groups. ${ }^{2-4}$ However, there is also the derivatization of secondary hydroxyl groups at positions 3 and 4, albeit to a lesser degree. Interestingly the enzymatic derivatization spectrum of inulin, which gives only single ester moieties, is distinct from the chemical derivatization of inulin reported in the literature. In fact, disubstituted fructofuranoside residues were found in inulin when molar ratios of acylating agent and inulin reported in this work were used in carboxymethyl and cyanoethylation reactions. ${ }^{32}$

Preparation and Characterization of Inul-VA Gels. The acrylate groups in Inul-VA were polymerized to form a crosslinked network. The polymerization proceeded quickly, and within ca. $5 \mathrm{~min}$ the solution started to gel. The minimal DS values necessary to gel 40, 20, and $10 \%$ (w/v) Inul-VA solutions in the presence of a free radical initiator were 7.4, 14.3 , and $23.8 \%$, respectively.

To follow the polymerization reaction, CP/MAS ${ }^{13} \mathrm{C}$ NMR spectroscopy was performed (more conventional FTIR spectroscopy could not be used due to the overlapping inulin bands with vinyl monomer bands at $1635 \mathrm{~cm}^{-1}$ (stretching of $\mathrm{C}=\mathrm{C}$ bond) and ca. $811 \mathrm{~cm}^{-1}$ (twisting of $\mathrm{CH}$ bond, from vinyl group) (data not shown)). CP/MAS ${ }^{13} \mathrm{C}$ NMR spectra of unreacted Inul-VA and after $24 \mathrm{~h}$ of polymerization are displayed in Figure 8. Upon polymerization the carbon from the carbonyl group is shifted from $\delta 169.3$ to $\delta 177.8 \mathrm{ppm}$ as a result of a hybridization change in the adjacent carbons (vinyl carbons) from $\mathrm{sp}^{2}$ to $\mathrm{sp}^{3}$. Furthermore, the tertiary methine carbon from the vinyl group shifts from $\delta 139.1$ to
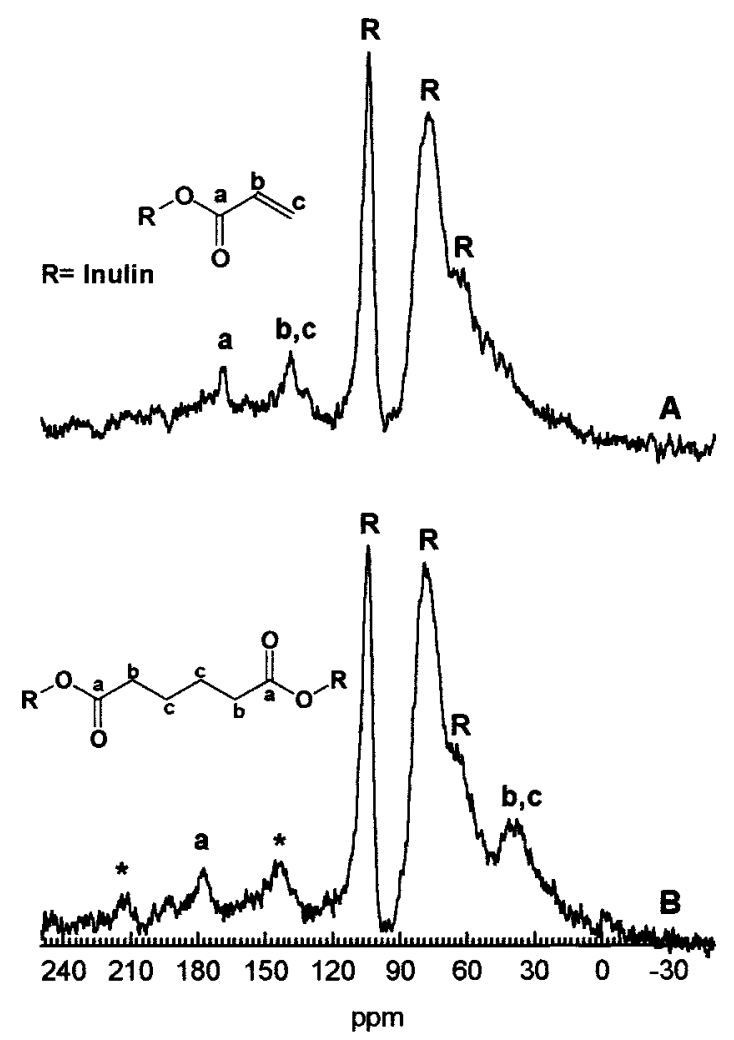

Figure 8. Solid-state CP/MAS ${ }^{13} \mathrm{C}$ NMR spectra of Inul-VA (DS = $28.7 \%$ ) in the beginning (A) and after $24 \mathrm{~h}(\mathrm{~B})$ of the polymerization reaction. The peaks labeled with an asterisk represent spinning sidebands.

$\delta 39.8$ ppm, while the secondary methylene carbon at 131.7 $\mathrm{ppm}$ is shifted to around $55 \mathrm{ppm},{ }^{20}$ overlapped by inulin carbons. Even if the degree of conversion of the acrylate groups could not be quantitatively determined by CP/MAS ${ }^{13} \mathrm{C} \mathrm{NMR}$, the results confirm the polymerization of vinyl monomers attached to inulin.

The determination of structural properties of cross-linked structures is crucial for gel characterization. The determination of the polymer volume fraction before and after swelling allows the calculation of the molecular weight between cross-links, $\bar{M}_{\mathrm{c}}$, according to eq 2 . This equation, developed by Peppas et al., ${ }^{23}$ describes the swelling of a highly cross-linked, moderately swollen polymeric network. This approach takes into account the small average chain length between cross-links (fewer than 100 repeating units), which deviates from a Gaussian distribution. ${ }^{23}$ Another critical parameter of gels is their average mesh size, $\xi$, which is important to assess the transport properties of solutes. $\xi$ was calculated from $\bar{M}_{\mathrm{c}}$ by eqs 3 and 4 .

SRE, $\bar{M}_{\mathrm{c}}$, and $\xi$ from Inul-VA gels were determined as a function of monomer concentration and degree of substitution of the monomers and are given in Table 2 . SRE, $\bar{M}_{\mathrm{c}}$, and $\xi$ decrease as the monomer concentration increases from 10 to $40 \%(\mathrm{w} / \mathrm{v})$, while maintaing a constant DS of Inul-VA monomer (28.7\%). SRE and $\xi$ decreases from 19.80 to 2.73 and from 56.83 to $19.11 \AA$, respectively. Furthermore, maintaining a constant monomer concentration $(40 \% \mathrm{w} / \mathrm{v})$ the SRE, $\bar{M}_{\mathrm{c}}$, and $\xi$ decrease as monomer DS increases in the starting polymerizing solutions. In this case, SRE and $\xi$ decreases from 6.05 to 2.71 and from 34.03 to $19.00 \AA$, 
Table 2. Network Properties of Inul-VA Gels as a Function of the Initial Monomer Concentration and the DS

\begin{tabular}{ccccccc}
\hline gel & $W_{0}^{a}(\%, \mathrm{w} / \mathrm{v})$ & $\mathrm{DS}^{b}(\%)$ & \multicolumn{1}{c}{$\mathrm{SRE}^{c}$} & $v_{2, S^{d}}$ & $\bar{M}_{\mathrm{c}}{ }^{e}(\mathrm{~g} / \mathrm{mol})$ & $\xi^{f}(\AA)$ \\
\hline 1 & 10 & 28.7 & $19.80 \pm 0.09$ & $0.048 \pm 0.001$ & $1640.6 \pm 1.6$ & $56.83 \pm 0.09$ \\
2 & 20 & 19.3 & $12.03 \pm 0.30$ & $0.077 \pm 0.002$ & $1535.2 \pm 12.4$ & $47.04 \pm 0.36$ \\
3 & 20 & 23.8 & $8.04 \pm 0.21$ & $0.111 \pm 0.003$ & $1268.6 \pm 20.8$ & $37.86 \pm 0.29$ \\
4 & 20 & 28.7 & $5.64 \pm 0.01$ & $0.151 \pm 0.001$ & $956.4 \pm 1.1$ & $29.65 \pm 0.01$ \\
5 & 40 & 14.3 & $6.05 \pm 0.13$ & $0.142 \pm 0.003$ & $1209.9 \pm 18.1$ & $34.03 \pm 0.21$ \\
6 & 40 & 19.3 & $3.59 \pm 0.06$ & $0.218 \pm 0.003$ & $769.3 \pm 13.8$ & $23.53 \pm 0.11$ \\
7 & 40 & 23.8 & $3.31 \pm 0.11$ & $0.232 \pm 0.006$ & $709.4 \pm 24.5$ & $22.12 \pm 0.19$ \\
8 & 40 & 28.7 & $2.73 \pm 0.15$ & $0.269 \pm 0.010$ & $583.7 \pm 31.2$ & $19.11 \pm 0.25$ \\
9 & 40 & 44.4 & $2.71 \pm 0.03$ & $0.270 \pm 0.002$ & $579.3 \pm 6.7$ & $19.00 \pm 0.05$ \\
\hline
\end{tabular}

${ }^{a}$ Initial monomer concentration. ${ }^{b}$ Degree of substitution, i.e., the amount of vinyl groups per 100 fructose units, determined by ${ }^{1} \mathrm{H}$ NMR. ${ }^{c}$ Swelling ratio at equilibrium (average $\pm \mathrm{SD}, n=3$ ). ${ }^{d}$ Polymer fraction at equilibrium swelling (average $\pm \mathrm{SD}, n=3$ ). ${ }^{e}$ Molecular weight between cross-links (average $\pm \mathrm{SD}, n=3$ ). ${ }^{f}$ Average mesh size (average $\pm \mathrm{SD}, n=3$ ).

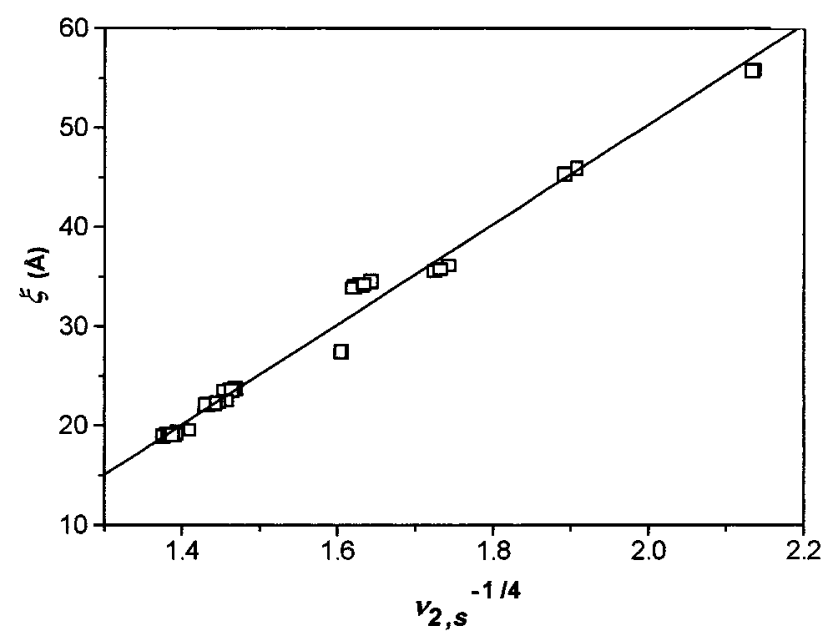

Figure 9. Relationship between the mesh size $(\xi)$ and the equilibrium polymer volume fraction $\left(v_{2, \mathrm{~s}}\right)$ for all Inul-VA gels prepared in this work. The straight line indicates the linear regression of the data with $r^{2}=$ 0.9923.

respectively. Both results can be explained by the increasing of cross-linking (intermolecular cross-links and polymer chain entanglements) formed at higher monomer (Inul-VA) concentrations and as monomer DS increases, which restricts network expansion upon swelling.

The calculation of both $v_{2, \mathrm{~s}}$ and $\xi$ for Inul-VA gels allows us to establish a correlation among these parameters. Since $v_{2, \mathrm{~s}}$ can be easily determined by the swelling of the crosslinked network, a correlation between $v_{2, \mathrm{~s}}$ and $\xi$, it was important to determine which solute could be applied in these gels. According to deGennes ${ }^{33}$ for semidilute polymer solutions $\left(v_{2, \mathrm{~s}} \leq 0.01\right), \xi$ is related to $v_{2, \mathrm{~s}}$ by a power-law exponent of -0.75 . At high polymer concentrations $\left(v_{2, \mathrm{~s}}>\right.$ 0.01 ) power-law exponents of $-0.5^{34}$ and $-1^{26}$ were reported on the literature. Inul-VA gels were analyzed using eq 9, using a linear regression with a predetermined exponent $n$

$$
\xi=k_{1}+k_{2} v_{2, s}{ }^{n}
$$

For the data of Inul-VA hydrogels with $v_{2, s}$ between 0.048 and 0.270 , eq 9 with $n=-0.25, k_{1}=-50.4, k_{2}=50.4$ gives a good correlation $\left(r^{2}=0.9923\right)$ (Figure 9). It is noteworthy that all hydrogel samples were prepared from different initial polymer and cross-linker concentrations, and the correlation obtained seems to extend to all gels prepared. The average mesh size range achieved for Inul-VA gels suggests that they may have applications in controlled release of compounds with low molecular weight (high cross-linked gels) or macromolecular compounds such as proteins (low cross-linked gels). In this case, globular proteins with a molecular weight of $30000 \mathrm{Da}$ which have a diameter ${ }^{35}$ of $\cong 42 \AA$ could be administered through gels 1 and 2 (Table 2).

\section{Conclusions}

This work reports the first successful enzyme-catalyzed modification of a soluble polysaccharide, in this case inulin, in anhydrous DMF. Incorporation of vinyl groups in the inulin backbone was accomplished by transesterification of inulin with vinyl acrylate catalyzed by Proleather. The efficiency of the transesterification reaction and the isolated yield were above 57.4 and $44.0 \%$, respectively. The structure of inulin esters revealed one predominant positional isomer in the fructofuranoside residue at the 6 position and two minor isomers at the 3 and 4 positions. Upon free radical polymerization of aqueous solutions of Inul-VA, hydrogels were obtained, which may have properties ideal for use as colon-specific drug delivery systems. The calculated values of $\bar{M}_{\mathrm{c}}$ varied between 579.3 and $1640.6 \mathrm{~g} / \mathrm{mol}$, which corresponded to an average mesh size of $19.00-56.83 \AA$. A correlation was established between $\xi$ and $v_{2, \mathrm{~s}}$. The exponent of this correlation was found to be -0.25 , and it allows definition of which drug solutes may be loaded in the inulin gels by the simple determination of their swelling characteristics.

The enzymatic process described herein can be envisioned as a new method for the modification of polymers in nonaqueous media. We are presently using this enzymatic approach to derivatize other polysaccharides and hydroxylated polymers.

Acknowledgment. We are grateful for the financial support of Fundação para a Ciência e a Tecnologia (Praxis XXI, BD/18456/98) to L.F. and the Biotechnology Research and Development Corporation to J.S.D.

\section{References and Notes}

(1) Schmid, A.; Dordick, J. S.; Hauer, B.; Kiener, A.; Wubbolts, M.; Witholt, B. Nature 2001, 409 (11), 258-267.

(2) Patil, D. R.; Dordick, J. S.; Rethwisch, D. G. Macromolecules 1991 24 (11), 3462-3463. 
(3) Rich, J. O.; Bedell, B. A.; Dordick, J. S. Biotechnol. Bioeng. 1995, $45,426-434$

(4) Riva, S.; Chopineau, J.; Kieboom, A. P. G.; Klibanov, A. M. J. Am. Chem. Soc. 1988, 110, 584-589.

(5) Carrea, G.; Riva, S. Angew. Chem., Int. Ed. 2000, 39, 2226-2254.

(6) Koeller, K. M.; Wong, C.-H. Nature 2001, 409, 232-240.

(7) Chaudhary, A. K.; Beckman, E. J.; Russell, A. J. Biotechnol. Bioeng. 1997, 55 (1), 227-239.

(8) Chaudhary, A. K.; Beckman, E. J.; Russell, A. J. J. Am. Chem. Soc. 1995, 117, 3728-3733.

(9) Al-Azemi, T.; Bisht, K. S. Macromolecules 1999, 32, 6536-6540.

(10) Bisht, K. S.; Svirkin, Y. Y.; Henderson, L. A.; Gross, R. A. Macromolecules 1997, 30, 7735-7742.

(11) Patil, D. R.; Rethwisch, D. G.; Dordick, J. S. Biotechnol. Bioeng. 1991, 37, 639-646.

(12) Park, O.-J.; Kim, D.-Y.; Dordick, J. S. Biotechnol. Bioeng. 2000, 70 (2), 208-216.

(13) Jarvie, A. W. P.; Overton, N.; Pourçain, C. B. S. J. Chem. Soc., Perkin Trans. 1 1999, 2171-2176.

(14) Bruno, F. F.; Akkara, J. A.; Ayyagari, M.; Kaplan, D. L.; Gross, R.; Swift, G.; Dordick, J. S. Macromolecules 1995, 28, 8881-8883.

(15) Li, J.; Xie, W.; Cheng, H. N.; Nickol, R. G.; Wang, P. G. Macromolecules 1999, 32, 2789-2792.

(16) Kumar, G.; Bristow, J. F.; Smith, P. J.; Payne, G. F. Polymer 2000 , 41, 2157-2168.

(17) Verraest, D. L. Ph.D. Thesis, Delft University Press: Netherlands, 1997.

(18) Roberfroid, M. B.; Van Loo, J. A. E.; Gibson, G. R. J. Nutr. 1998 , $128,11-19$.
(19) Niness, K. R. J. Nutr. 1999, 129 S (7S), 1402S-1406S.

(20) Vervoort, L.; Van den Mooter, G.; Augustijns, P.; Busson, R.; Toppet, S.; Kinget, R. Pharm. Res. 1997, 14 (12), 1730-1737.

(21) Schonbaum, G. R.; Zerner, B.; Bender, M. L. J. Biol. Chem. 1961, 236, 2930-2935.

(22) Flory, P. J.; Rehner, R. J. Chem. Phys. 1943, 11, 521-526.

(23) Peppas, N. A.; Moynihan, H. J.; Lucht, L. M. J. Biomed. Mater. Res. 1985, 19, 397-411.

(24) Azis, B. H.; Chin, B.; Deacon, M. P.; Harding, S. E.; Pavlov, G. M. Carbohydr. Polym. 1999, 38 (3), 231-234.

(25) Gekko, K. In ACS Symp. Ser. 1981, No. 150, 415-438.

(26) Canal, T.; Peppas, N. A. J. Biomed. Mater. Res. 1989, 23, 11831193

(27) Ferreira, L.; Gil, M. H.; Dordick, J. S. Manuscript in preparation.

(28) Uyama, H.; Kobayashi, S. Chem. Lett. 1994, 1687-1690.

(29) The conversion is defined as the percentage of acrylate groups attached to inulin taking into account the initial molar ratio of VA to inulin fructose units in the reaction mixture $(\times 100)$.

(30) Verraest, D. L.; Peters, J. A.; Batelaan, J. G.; Van Bekkum, H Carbohydr. Res. 1995, 271, 101-107.

(31) Yoshimoto, K.; Itatani, Y.; Tsuda, Y. Chem. Pharm. Bull. 1980, 28 (7), 2065-2076.

(32) Verraest, D. L.; Peters, J. A.; Kuzee, H. C.; Raaijmakers, H. W. C.; van Bekkum, H. Carbohydr. Res. 1997, 302, 203-212.

(33) deGennes, P. G. Macromolecules 1976, 9, 587-593.

(34) Muthukumar, M.; Edwards, S. F. Polymer 1982, 23, 345-348.

(35) Chapman, J. D.; Hultin, H. O. Biotechnol. Bioeng. 1975, 17, 1783-1795.

BM010150H 